\title{
RELASI ISLAM DAN POLITIK DI INDONESIA (Perdebatan Seputar Ideologi dan Konstitusi Negara Indonesia Merdeka) Oleh: Wahyuddin G. \\ Wahyuddin.uin58@gmail.com
}

Lecturer of Adab and Humanities Fuculty of Alauddin State Islamic University of Makassar

\begin{abstract}
Islam and Politic have interrelationships. It consists of fungtional Islam and politics is a unity that can not be separated. Islam and politics have the correlation functional; Islam requires political support, while the political needs of moral and ethics of Islam. The relationship between Islam and politics can be viewed from two aspects. Firstly, there are several doctrines aspect, the phrase of the Qur'an which is often interpreted as a political concept referring to Islam. Second, the social reality. Having been Hijrah Year $622 \mathrm{H}$., the Prophet Muhammad Saw., has formed the Government of Madinah through a political contract with residents of the city of Madinah, consisting of Jewish, Islamic, and Arabian community who still adhere to the traditions and ignorance. The political contract is defined into a shahifah, and then it is known 'Madinah Charter'. At the time, a small Committee was formed which compromises between the nasinalism and Islam to stem the various differences between the Islamic and the secular nationalists in BPUPKI who designed the Preamble and the Declaration of the independence day of Indonesia. This small Committee is managed to formulate the script 'Jakarta Charter'. In essence, the Charter affirms the Pancasila as the ground state with the addition of a sentence on the sila of the Godhead to be: believe in God with the obligation of running Islamic jurisprudence for the hangers. The next compromise occurred on August $18^{\text {th }} 1945$, changing the clause of the divinity with the obligation of running Islamic jurisprudence for the hangers which becomes "the divinity of the one true God".
\end{abstract}

Keywords: Ideology, Constitution, Sharia, Politics.

\section{A. Pendahuluan}

Sepanjang sejarah Indonesia, umat Islam mengalami pasang surut dalam perjuagan politiknya. Pada masan kerajaan-kerajaan Nusantara, politik Islam cenderung menyatu dengan agama. Dalam hal ini, para ulama memainkan peran 
penting di dalam kerajaan dan cenderung menjadi alat justifikasi kekuasaan sultan ${ }^{1}$. Ketika Belanda masuk menjajah Indonesia, pemerintah jajahan Hindia Belanda menjalankan praktek politik Islam untuk membatasi ruang gerak umat Islam dengan membenturkan kelompok Islam dan kelompok adat atau netral agama.

Para ulama pun tampil memainkan peranan penting dalam menggerakkan perlawanan terhadap penjajahan. Terjadilah pemborantakan di berbagai wilayah Nusantara. Di Aceh, di bawah pimpinan Teuku Umar, Cik Di Tiro, Cut Nyak Din. Di Minangkabau terjadi Perang Paderi yang bermula dari perselisihan kaum agama yang dipimpin oleh Imam Bonjol dan kaum adat, kemudian dimanfaatkan politik adu domba penjajah Belanda. Di Jawa, perlawanan terhadap Belanda dipimpin oleh Pangeran Diponegoro, di Sulawesi Selatan dipimpin oleh Sultan Alauddin, Sultan Hasanuddin. Di Kalimanatan dipimpin oleh Pangeran Antasari. Demikian pula di daerah lain, para ulama bersama para sultan bergolak melawan penjajah Belanda. Pasca kemerdekaan Indonesia, pemikiran dan peran politik umat Islam menjadi sesuatu yang sangat dinamis, berhadapan dengan kelompok nasionalis netral agama atau nasionalis sekuler.

Islam dan politik memang merupakan satu kesatuan yang tidak dapat dipisahkan. Islam dan politik terdapat korelasi fungsional, Islam memerlukan dukungan politik, sementara politik membutuhkan moral dan etika Islam. Hubungan antara Islam dan politik paling tidak dapat dilihat dari dua hal. Pertama, dari sisi Islam sebagai doktrin, terdapat beberapa ungkapan Alquran yang sering ditafsirkan sebagai konsep politik menurut Islam. ${ }^{2}$ Kedua, hubungan Islam dan politik dapat ditelusuri dalam masyarakat Islam sebagai realitas soaial. Rasulullah SAW di Madinah pasca hijrah tahun $622 \mathrm{M}$, telah membentuk pemerintahan Madinah melalui kontrak politik antara Rasulullah dengan penduduk kota yang terdiri atas kelompok Yahudi, kelompok Anshar, kelompok Muhajirin, dan masyarakat Arab yang masih menganut tradisi jahiliah. Kontrak politik yang dituangan dalam sebuah shahifah kemudian dikenal dengan nama Piagam Madinah. Kontrak politik itu menunjukkan suatu kesepakatan Nabi dan penduduk Madinah untuk mendirikan suatu Negara Madinah (City state) dengan Nabi Muhammad SAW sebagai kepala Negara. ${ }^{3}$ Sejak

\footnotetext{
${ }^{1}$ Muhammad Iqbal dan Amin Husein Nasution, Pemikiran Politik Islam: dari Masa Klasik hingga Indonesia Kontemporer (edisi revisi, cet. 2, Jakarta, Kencana, 2013), h. 255.

${ }^{2}$ Misalnya: Kepunyaan Allah kerajaan langit dan bumi (QS. 5, al- Maidah: 17-18), difahami bahwa seluruh kekuasaan, termasuk kekuasaan politik menurut Islam berada pada Allah, kekuasaan itu kemudian dilimpahkan kepada manusia sebagai khalifah (QS. 2 al-Baqarah: 30). Ungkapan 'ulil amri (QS. 4 al. Nisa: 59) menunjukkan perlunya pemerintahan dalam masyarakat. Sementara itu, kata syura' (QS al-Syura: 42) dan syawir (QS. 3, Ali Imran: 159), kedua ayat itu difahami sebagai konsep politik yang memberikan petunjuk tentang perlunya pengambilan keputusan secara musyawarah dan demokratis oleh pemegang kekuasaan. Lihat M. Saleh Ahmad Putuhena, Islam dan Politik: Pergumulan tanpa Akhir, Rekonstruksi Pantulan Pengalaman Indonesia (Pidato Penerimaan Jabatan Guru Besar dalam Bidang Sejarah dan Kebudayaan Islam pada Fakultas Adab IAIN Alauddin Makassar, Makassar, 11 Nopember 2004), h. 3.

${ }^{3}$ Lihat M. Saleh Ahmad Putuhena, Islam dan Politik: Pergumulan Tanpa Akhir, Rekonstruksi Pantulan Pengalaman Indonesia (Pidato Penerimaan Jabatan Guru Besar Sejarah dan Kebudayaan Islam pada Fakultas Adab IAIN Alauddin Makassar, Makassar, 11 Nopember 2004), h.4.
} 
itu, Islam atau tepatnya masyarakat Islam tidak dapat dipisahkan dengan politik yang inherent dengan masyarakat itu sendiri.

Secara teori, umat Islam percaya bahwa ajaran Islam itu meliputi seluruh dimensi kemanusiaan. Dengan kata lain apa yang disebut masalah sekuler, di mata seorang muslim tidak dapat dipisahkan dengan persoalan imannya. Dari sudut pandang ini, cita-cita kekuasaan politik menyatu dengan wawasan moral sebagai pancaran dari iman seorang muslim. Politik, dengan demikian tidak dapat dipisahkan dari ajaran etik yang bersumber dari wahyu.

Bila konsep teoritik di atas kita bawa ke dalam masyarakat Indonesia yang mayoritas muslim, maka kita dihadapkan pada dua fenomena sosiologis yang tidak saja berbeda, tetapi bisa jadi bertentangan. Fenomena pertama adalah umat yang menjadi pendukung pelaksanaan syariat dalam kehidupan individu dan kehidupan kolektif. Mereka adalah pendukung partai dan organisasi dengan label Islam, atau label lain yang menunjukkan kepada makna yang sama. Fenomena lain adalah kelompok umat Islam Indonesia yang mungkin karena pengaruh cita-cita politik Barat sekuler, berpandangan bahwa politik adalah semata kegiatan duniawi, sedangkan agama adalah persoalan individu yang tidak perlu dikaitkan dengan masalah politik.

Mereka yang dapat dikategorikan pada kelompok pertama adalah mereka yang berpandangan bahwa Islam merupakan pandangan hidup yang lengkap dan sempurna. Tidak ada kegiatan hidup betapa pun kecilnya yang lepas dari sorotan iman. Golonga ini biasa disebut golongan nasionalis Islami. Sebaliknya, mereka yang biasa dimasukkan pada kategori kedua adalah mereka yang tidak begitu hirau dengan praktek-praktek dan upacara-upacara keagamaan dan membatasi diri pada halhal yang berkaitan dengan tahap-tahap yang terpenting dalam kehidupan, seperti kelahiran, perkawinan, dan kematian. Golongan ini dikenal dengan sebutan nasionalis sekuler atau nasionalis netral agama. Dua pandangan ini sama-sama mempengaruhi perjalanan sejarah kontemporer Indonesia, sekali pun sikap komromi kedua golongan ini sering juga menjadi kenyataan. Dinamika pergumulan pemikiran dan gerakan kelompok Islamis dan kelompok sekuler atau netral agama dalam perjalanan sejarah politik Indoneia menjadi menjadi pokok bahasan tulisan ini. Pembahasan itu bertujuan memahami pemikiran dan gerakan kedua kelompok tersebut, sekaligus berupya menemukan gagasan alternatif kompromis untuk membangun Indonesia ke depan yang berkarakter kemanusiaan di atas landasan religiusitas.

\section{B. Islam Politik dan Politik Islam Indonesia}

Mendahului pembahasan tentang Islam politik dan politik Islam $^{5}$ di Indonesia, diperlukan pengenalan tentang sejarah Islam Indonesia, guna memahami

\footnotetext{
${ }^{4}$ Syafii Maarif, Islam dan Plotik di Indonesia Pada Masa Demokrasi terpimpin (1959-1965), (Yogyakarta, IAIN Sunan Kalijaga Press, 1988), h. 13.

${ }^{5}$ Islam politik adalah pandangan dan gerakan kalangan Islamis baik perorangan, organisasi social, maupun partai politik yang mengusung Islam sebagai idiologi politik, yaitu Islam sebagai dasr Negara atau setidak-tidaknya syariat Islam diakui oleh Negara, meskipun hanya berlaku buat pemeluknya. Sedangkan politik Islam adalah sikap dan gerakan penguasa atau kelompok yang nenolah ajaran Islam dijadikan sebagai sebagai idiologi politik. Lihat M. Saleh Ahmad Putuhena, Islam dan
} 
latarbelakang munculnya kedua kelompok tersebut dalam percaturan perpolitikan di Indonesia. Di kalangan ahli, terdapat perberbedaan pendapat tentang masuknya Islam di Indonesia. Azyumardi Azra menyatakan bahwa perbedaan mereka menyangkut masalah-masalah tempat asal ke datangan Islam, para pembawa, dan waktu kedatangannya. Perbedaan itu kemudian melahirkan banyak teori tentang masuknya Islam di Indonesia. Di antaranya: pertama, teori yang menyebutkan bahwa Islam masuk pertama kali ke Nusantara (Indonesia) pada abad ke 12 dari Gujarat dan Malabar, bukan dari Persia atau Arab. Teori ini dikembangkan oleh Pijnappel pada tahun 1872, dan umumnya didukung oleh sarjana-sarjana Belanda, seperti Snouch Hurgronye, Muquitte, dan Morisson. Teori ini menyatakan bahwa orang-orang Arab yang bermazhab Syafii bermigrasi ke India kemudian membawa agama Islam ke Nusantara. ${ }^{6}$ Kedua, teori yang dikemukakan oleh S.Q. Fathimi, yang menyatakan bahwa Islam datang ke Indonesia berasal dari Benggali. Ia berargumentasi bahwa kebanyakan orang-orang terkemuka di Pasai adalah orang-orang Benggali atau keturunan mereka. Islam muncul pertama kali di semenanjung Malaya pada abad ke$11 \mathrm{M}$ adalah dari Pantai Timur, bukan dari Barat (Malaka) melalui Kanton, Panrang (Vietnam), Leran, dan Trengganu. ${ }^{7}$

Teori ketiga, menyatakan bahwa Islam datang ke Indonesia langsung dari Arab, tepatnya Hadhramaut. Teori ini pertama kali dikemukakan oleh Craufurd (1820), didukung oleh Salomon Keyzer (1859), Niemann (1861), de Hollander (1861), dan Verth (1874). Teori menyatakan bahwa Islam yang masuk ke Nusantara berasal langsung dari Arab. Pendukung teori ini mengajukan pandangan bahwa pedagang-pedgang dari Arab sendiri memegang peranan dominan dalam menyebarkan Islam ke Nusantara, bahkan sejak abad ke-7 dan 8 Masehi atau awal abad pertama Hijeriah. Bahkan pada tahun 674 M di Pantai Barat Sumatera sudah didapati satu perkampungan orang-orang Arab. ${ }^{8}$

Teori ini dianut pula oleh sarjana Melayu, Syed Hussen Naquib al-Attas dan Hamka. Dalam seminar tentang masuknya Islam di Indonesia di Medan pada 17-20 Maret 1963, Hamka menyimpulkan bahwa Islam telah masuk ke Indonesia pada abad ke-7 dan 8 Masehi. Hamka bahkan mengecam teori Hurgronye dan kawan-kawannya serta menyatakan bahwa teori tersebut adalah salah satu ilmiah Belanda dalam rangka melemahkan dan mematahkan perlawanan Islam terhadap Belanda. Snouch Hurgronye sendiri adalah penasehat utama pemerintah Hindia Belanda dalam rangka menaklukkan Aceh. Menurut Hurgronye, salah satu sebab kerasnya perlawanan

Politik Pergumulan Tanpa Akhir Rekonstruksi Pantulan Pengalaman Indonesia. (Makassar, IAIN Alauddin, 2004), h. 6-7.

${ }^{6}$ Azyumardi Azra, Jaringan Ulama Timur Tengah dan Kepulauan Nusantara Abad XVII dan XVIII Melacak Akar-Akar pembaruan Pemikiran Islam di Indonesia, (Bandung, Mizan, 1994), h. 25.

${ }^{7}$ Muhammad Iqbal dan Amin Husein Nasution, Pemikiran Politik Islam: dari Masa Klasik hingga Indonesia Kontemporer (edisi revisi, cet. 2, Jakarta, Kencana, 2013), h. 257.

${ }^{8}$ Muhammad Iqbal dan Amin Husain Nasution, Pemikiran Politik Islam dari MasaKelasik Hingga Indonesia Kontemporer, h. 257. 
rakyat terhadap Belanda, karena berurat berakarnya pengaruh Arab. Oleh karena itu, ia ingin melemahkan perlawanan tersebut dengan mengembangkan teori India. ${ }^{9}$

Terlepas dari perbedaan pendapat tentang tempat asal, pembawa, dan waktu masuknya Islam di Indonesia, Uka Tjandrasasmita berusaha melakukan kompromi dengan menyatakan bahwa kedatangan Islam di Indonesia sejak abad ke-7 sampai abad ke-12 di berbagai daerah Asia Tenggara dapat dikatakan bahwa baru pada tahap awal pembentukan komunitas muslim, terutama terdiri dari para pedagang. Abad ke13 sampai abad ke-16, terutama dengan munculnya kerajaan yang bercorak Islam, merupakan kelanjutan dari penyebaran Islam tahap awal. ${ }^{10}$

Ketika datang pada gelombang pertama, Islam menghadapi masyarakat kerajaan yang bercorak Hindu-Budha, yang masyarakatnya masih memiliki struktur pemerintahan yang kuat dengan kepercayaan dinamisme dan animism. Apabila gelombang pertama hanya menghasilkan komunitas muslim, terutama terdiri dari para pedagang muslim, penyebaran Islam masih sangat terbatas, maka gelombang kedua sejak abad ke-13, penyebaran Islam telah mantap dan meluas, karena sejak abad ke13 di pesisir Aceh Utara di daerah Lhokseumawe muncul kerajaan Islam yang pertama di Asia Tenggara. Memasuki abad ke-16 dan awal abad ke-17 merupakan puncak penyebaran Islam di Indonesia dengan berdiri kerajaan-kerajaan yang bercorak Islam hampir di seluruh wilayah Indonesia, seperti Sumatera, Jawa, Maluku, Sulawesi, Kalimantan dan sebagainya. Dengan demikian, sekitar abad ke-16, perdagangan kerajaan-kerajaan Islam masuk ke dalam jalur yang terkait dalam pelayaran dan perdagangan internasional. Di dalamnya terlibat pedagang-pedang Cina, Arab, Persia, India, Malaka, Tumasik, Johor, Pasai, Aceh, Palembang, Jawa Timur, Madura, Sulawesi, Maluku, dan lainnya.

Keterlibatan bangsa-bangsa Barat, seperti Portugis, Spanyol, Belanda, dan Inggeris dalam perdagangan internasional di Indonesia mendapat reaksi keras dari para sultan, mula-mula kehadiran mereka dinggap sebagai gangguan budaya, terutama karena perbedaan agama. Pada tahap ini mereka digambarkan sebagai orang kafir, disertai dengan berbagai konotasi negatif lainnya, seperti, licik, kikir, dan mudah ingkar janji. ${ }^{11}$ Oleh karena itu, mudah sekali bagi para penguasa Islam membangun suatu idiologi yang menyakralkan perlawanan terhadap penjajah dengan melancarkan perang suci atau jihad fi sabilillah.

Dalam banyak kasus, perlawanan terhadap penjajah, khususnya Belanda, selain faktor ekonomi, faktor agama sangat menonjol. ${ }^{2}$ Sultan Agung, (1613-1646),

${ }^{9}$ Hamka, Masuk dan Berkembangnya Agama Islam di Daerah Pesisir Sumatera Utara, dalam Risalah Seminar Masuknya Islam ke Indonesia, (Medan, Panitia Sejarah Masuknya Agama Islam ke Indonesia, 1963), 79-81.

${ }^{10}$ Uka Tjandrasasmita, Kedatangan dan Penyebaran Islam, dalam Taufik Abdullah dkk (ed), ensiklopedia Tematis Dunia Islam, Volume 5, (Jakarta, PT Ikhtiar Baru Van Hoeve, 2003), h. 12.

${ }^{11}$ Muhammad Iskandar dan Ahmad Syahid, Islam dan Kolonialisme, dalam Taufik Abdullah dkk (ed), Ensiklopedi Tematis Dunia Islam, Volume 5, h. 322.

${ }^{12}$ Sebagaimana diketahui bahwa fakor yang mendorong Portugis dan Spanyol mencari jalan ke Kepulauan rempah-rempah adalah fakto ekonomi, agama, petualangan atau kekuasaan, demikian juga dengan kolonial Beanda. Dengan dorongan ketiga factor ini, mereka melakukan pelayaran hingga 
penguasa Mataram, Sultan Alauddin dan Sultan Hasanuddin, Gowa-Makassar pada abad ke-17, juga memiliki pandangan yang sama, begitu juga sultan Palembang dan Sultan Siak, berturut-turut abad ke-18 dan abad ke-19. Bahkan ketika berkecamuk perang, Muhammad Amin, atau Teuku Cik Di Tiro, seorang tokoh yang sangat berpengaruh di Aceh, pada 1885 menulis surat kepada panglima Belanda yang berisi pernyataan bahwa Perang Aceh (1873-1909) akan berakhir dengan damai hanya dapat ditegakkan jika Belanda masuk Islam. ${ }^{13}$

Dapat dikatakan bahwa konflik, perang atau pemberontakan pada abad ke-17 hingga paruh kedua abad ke-19 dilatari oleh idiologi jihad fi sabilillah. hal ini pula yang mendorong Sultan Abdul Fatah, terkenal dengan Sultan Ageng Tirtayasa (16511692) menentang putra mahkota, Sultan Haji yang bersekutu dengan Belanda. Penentangan ini dilanjutkan oleh menantu Sultan Ageng, Syech Yusuf al-Makassari hingga ditangkap dan dibuang ke Afrika. Pemberontakan yang dimotori kalangan aristokrat seperti Pangeran Mangkubumi dan Raden Mas Said abad ke-18, Pangeran Diponegoro dalam Perang Jawa (185-1830); Teuku Umar, Teuku Cik Ditiro, Cut Nyak Dien, dan Cut Mutia dalam Perang Aceh; Sultan Thaha di Jambi pada akhir abad ke-19, dapat dijadikan contoh tentang terjadinya sakralisasi perang melawan Belanda berdasarkan justifikasi agama. Demikian juga model pemberontakan yang melibatkan para haji, seperti dalam pemberontakan di Banjarmasin, Kalimantan Selatan (1859); Kasus Haji Rifa'I dari Kalisasak (1859); peristiwa Cianjur, Sukabumu (1885); pemberontakan petani Cilegon, Banten (1888); Gerakan Petani Samin (18901917), dan peristiwa Garut (1919), semuanya digelorakan dengan semangat jihad $f i$ sabilillah.

Menghadapi perawanan terus-menerus yang dimotori para sultan dan kalangan ulama, pemerintah Hindia Belanda berupaya merumuskan kebijakan politik Islamnya terhadap daerah jajahan Indonesia. Dalam tataran praktik, mula-mula pemerintah Hindia Belanda mengakui keberadaan hukum Islam yang berlaku di dalam masyarakat muslim Nusantara, para gubernur jenderal Belanda membiarkan hukum Islam berjalan di masyarakat Sementara secara teoritis, beberapa sarjana Belanda mengemukakan teori keberlakuan hukum Islam bagi masyarakat muslim Nusantara, seperti Salomon Keyzer (1823-1868), Willem Kristian Van Den Berg (1845-1927). Keyzer menyatakan bahwa bagi umat Islam berlaku hokum Islam. Pandangan ini dilanjutkan Van Den Berg dengan mengembangkan teori Receptio in Coplexu. Bagi umat Islam berlaku hukum Islam, meskipun tidak harus sama dengan yang dipraktekkan oleh umat Islam Timur Tengah. ${ }^{14}$

sampai ke kepulauan Indonesia. Bagi orang-orang Portugis, raja-raja dan pedagang yang bukan beragama Islam dapat menjadi kawan, tetapi tidak demikian halnya dengan raja-raja dan pedagangpedagang Islam, harus dihancurkan dan dikuasai. Lihat Marwati Djoened Poespenogoro dan Nugroho Notosusanto, Sejarah Nasional Indonesia III, edisi ke-4 (Jakarta, Balai Pustaka, 1984), h. 41.

${ }^{13}$ Muhammad Iskandanr dan Ahmad Syahid, Islam dan Kolonialisme, dalam Taufik Abdullah dkk (ed), Ensiklopedi Tematis Dunia Islam, Volume 5, h. 322.

${ }^{14}$ Muhammad Iqbal dan Amin Husein Nasution, Pemikiran Politik Islam dari Masa Klasik Hingga Indonesia Kontemporer, Edisi Revisi, h. 267. 
Dengan pandangan demikian, pemerintah Belanda menempuh politik yang cenderung memberi ruang bagi umat Islam mengembangkan hukum Islam di Indonesia. Namun memasukui pertengahan abad ke-19, pemerintah Hindia Belanda mulai berusha keras mencampuri urusan keagamaan penduduk pribumi. Harry J. Benda menyebutkan bahwa orang-orang Belanda di negeri Belanda sendiri maupun di Indonesia mengharapkan supaya pengaruh Islam di daerah jajahannya dihilangkan dengan mempercepat Kristenisasi sebagaian besar orang Indoneia. Hal ini didasarkan pada anggapan orang Barat tentang superioritas ajaran Kristen atas Islam. ${ }^{15}$

Karena itu, Belanda membutuhkan politik hukum yang dapat melemahkan posisi Islam bagi umatnya. Pada tahun 1889 Belanda mendatangkan dan mengangkat seorang ahli agama Islam bernama Kristian Snouck Hurgronye (1857-1936), sebagai penasehat pemerintah jajahan Belanda. Snouck melakukan berbagai penyelidikan terhadap masyarakat Aceh dan beberapa daerah lain di Indonesia, seperti Batavia dan Banten. Dia berkesimpulan bahwa hukum yang berlaku bagi rakyat pribumipada dasarnya adalah hokum adat. Dialah sarjana Belanda yang pertama kali mempertentangkan antara hokum adat dan hukum Islam. Baginya, hukum Islam baru berlaku dalam masyarakat kalau norma-normanya sudah diakui dan diterima masyarakat tersebut, karena hukum Islam terserap dan menjadi bagian dari hukum adat. $^{16}$

Berkaitan dengan upaya mempertentangkan hukum adat dan hukum Islam, dalam salah satu nasehatnya kepada pemerintah Hindia Belanda, Snouck menyatakan bahwa adat, terutama di Minangkabau harus dipertahankan dan dibela dari propaganda kelompok agama yang ingin mengubahnya. Untuk itu, adat harus dibiarkan berkembang tetapi tetap berada dalam pengawasan pemerintah. Sifat kedaerahan dan keragaman adat juga harus dipupuk agar penduduk Hindia Belanda tidak punya kesatuan hokum. ${ }^{17}$ Dalam buku Politik Islam Pemerintah Hindia Belanda, Akib Suminto mencatat strategi yang dirumuskan Snouck menghadapi perlawanan umat Islam Indoneia. Pertama, dalam bidang agama murni (ibadah), pemerintah Hindia Belanda hendaknya memberikan kebebasan kepada umat Islam menjalankan ajaran agama mereka sepanjang tidak mengganggu kekuasaan Belanda, kedua, dalam bidang social kemasyarakatan, pemerintah memanfaatkan berbagai adat kebiasaan yang berlaku dalam masyarakat, ketiga, dalam bidang politik, pemerintah harus mencegah setiap usaha yang akan membawa masyarakat $t$ kepada panatisme politik Pan Islam. ${ }^{18}$

Politik Islam rumusan Snouch Hurgranye ini, menjadi strategis kebijakan pemerintah Hindia Belanda dalam menghadapi Islam. Dengan strategis itu pemerintah

\footnotetext{
${ }^{15}$ Harry J. Benda, The Cresent and the Rising Sun, diterjemahkan Dhaniel Dhakidae: Bulan Sabit dan Matahari Terbit Islam Indonesia pada Masa Pendudukan Jepang, (Jakarta, Pustaka Jaya, 1985), h. 39.

${ }^{16}$ Muhammad Iqbal dan Amin Husein Nasution, Pemikiran Politik Islam dari Masa Klasik Hingga Indonesia Kontemporer, Edisi Revisi, h. 268-269.

${ }^{17}$ C. Snouck Hurgronye, Kumpulan Karangan, Jilid x, (Jakarta, Inis, 1993), h. 146.

${ }^{18}$ Akib Suminto, Politik Islam Pemerintah Hindia Belanda, (Jakarta, LP3ES, 1996), h. 12.
} 
berupaya mempersempit ruang gerak Islam hanya sebagai ritual belaka dan mencegah munculnya Islam politik sebagai kekuatan untuk menentang kekuasaan Belanda. Selain itu, memberikan keleluasaan berkembangnya adat kebiasaan dan membenturkannya dengan Islam. Pemerintah Hindia Belanda berusaha meminggirkan peran hukum Islam dari kehidupan masyarakat dan mendukung adat setiap kali terjadi pertentangan antara kelompok Islam dan kelompok adat, sebagaimana yang terjadi di Sumatera Barat, tepatnya Minangkabau. Dalam perkembangan selanjutnya, setiap kali menghadapi serangan umat Islam, Belanda kemudian merangkul kelompok yang netral agama dan kaum adat, yang pada dasarnya juga beragama Islam. Dari sinilah cikal bakal perseteruan kelompok politik Islam dan Islam politik di Indonesia, kemudian menjelma menjadi perseteruan kelompok nasionalis netral agama atau sekuler dan kelompok Islam dalam perpolitikan di Indonesia, terutama menjelang dan awal-awal kemerdekaan.

Berbeda dari pemerintah kolonial Belanda, pemerintah pendudukan militer jepang menggunakan pengaruh ulama mendekatkan diri pada kelompok Islam dengan tujuan memenangkan perang di Asia Timur. Pemerintah pendudukan Jepang tampak lebih bersedia memberikan konsesi politik terhadap tuntutan kelompok Islam, daripada kelompok nasionalis sekuler apalagi kaun aristokrat atau priyayi. Konsesi tersebut mencakup pembentukan kantor urusan agama (shumubu), pendirian Majelis Syuro Muslimin Indonesia, dan pembentukan Hizbullah, organisasi militer untuk pemuda muslim. Dapat dikatakan bahwa pemerintah pendudukan Jepang mendorong tumbuhnya rasa percaya diri secara politik bagi kelompok Islam dalam menghadapi kawan-kawan mereka dari kelompok nasionalis. ${ }^{19}$ Inilah sebenar akar pertentangan antara kelompok nasionalis agamais dan kelompok nasionalis netral agama yang pada era menjelang kemerdekaan sangat menonjol muncul ke permukaan. Pertentangan ini bahkan lebih membara pada masa berikutnya, pasca kemerdekaan dengan menampilkan bentuk yang berbeda antara satu episode dari episode lainnya.

\section{Kolompok Nasionalis Islami VS Nasionalis sekuler dalam BPUPKI}

Masa pendudukan Jepang memberikan lebih banyak pengalaman kelembagaan kepada pemimpin Islam berkaitan dengan masalah pengaturan keagamaan Islam dalam sebuah Negara, tetapi, dengan semakin terpojoknya kekuatan militer Jepang di Asia, pemerintah pendudukan Jepang mengubah arah kebijakan mereka. Jepang semakin sering, bahkan secara terbuka mendukung para pemimpin kelompok nasionalis. Pemerintah pendudukan Jepang terlihat lebih mempercayai kelompok nasionalis sekuler memimpin Negara Indonesia masa depan. Sejalan dengan itu, pada tanggal 9 April 1945 dibentuk sebuah Badan Penyelidik Usahausaha Persiapan Kemerdekaan Indonesia (BPUPKI), dalam bahasa Jepang, Dokuritsu ZyunbiTyoosakai, sebagai realisasi dari janji Jepang yang akan memberikan kemerdekaan kepada Indonesia kelak di kemudian hari. Badan itu diketuai Rajiman Wedyodiningrat, seorang penganut mistik Jawa, berafiliasi pada kelompok nasionali sekuler.

\footnotetext{
${ }^{19}$ Bahtiar Effendi dan Ali Munhanif, Indonesia Pascakemerdekaan, dalam Taufik Abdullah dkk (ed), Ensiklopedi Tematis Dunia Islam, Volume 5, h. 432.
} 
Tugas BPUPKI adalah merumuskan bentuk Negara, batas Negara, dasar falsafah Negara, dan masalah-masalah lain yang perlu dimasukkan dalam konstitusi. Selain pembahasan dasar dan falsafah Negara, BPUPKI tidak menemui kesulitan yang berarti dalam kerja konstitusionalnya, karena memang dipandang tidak menyentuh masalah idiologi dasar yang biasa mengundang kepekaan psyikoemosional. Namun ketika masalah dasar falsafah Negara dibahas dalam sidang, suasana jadi lain, tegang, insten, dan sangat serius. Iman kaum santri yang duduk dalam BPUPKI terpancing dengan tarikan yang amat kuat. Dikabarkan seorang tokoh umat sampai memukul meja karena berang.

Dalam kompisisi anggota BPUPKI, kalangan nasionalis Islam hanya diwakili 15 orang dari 68 orang anggota BPUPKI. Tokoh-tokoh nasionalis Islam antara lain, K.H.A. sanusi dan KH Abdul Halim (PUI), Ki Bagus Hadikusumo, KH Mas Mansyur, dan Abd. Kahar Muzakkir (Muhammadiyah), KH. A. Wahid Hasyim, KH. Masykur (NU), Sukirman Wirjosanjoyo (PII), Abikusno Tjokrosujoso (PSII), Agus Salim (PSI-Penyadar). Selebihnya biasa dikatakan mewakili kelompok nasionalis sekuler, dengan tokoh utama, Sukarno, Muhammad Hatta, Rajiman Wediodiningrat, Ahmad Subarjo, Muhammad Yamin, Supomo dan Wonsonegoro. ${ }^{20}$

Dalam perdebatan tentang dasar dan falsafah Negara Indonesia merdeka, banyak pandangan yang terungkap, yang pada intinya terbelah dua kelompok. Kelompok Islam, dengan para tokohnya berpendirian bahwa negara harus didasarkan pada Islam, karena posisi agama Islam di Indonesia begitu mengakar. Pada sisi lain, kelompok nasionalis sekuler membela pandangan bahwa dalam rangka menyelamatkan kesatuan bangsa, dasar Negara haruslah netral dan tidak boleh dikaitkan dengan kepercayaan agama tertentu, khususnya Islam. Memperkokoh argument negara yang memisahkan masalah agama dan politik, Sukarno mengusulkan lima prinsif pokok, yang kemudian dikenal dengan Pancasila sebagai dasar filosofi negara, yaitu kabangsaan atau nasionalisme, kemanusiaan atau internasionalisme, musyawarah atau demokrasi, kesejahteraan, dan ketuhanan. ${ }^{21}$

Untuk menjembatani berbagai perbedaan antara golongan Islam dan golongan nasionalis sekuler dilakukan ketika BPUPKI mulai merancang Pembukaan UUD dan pernyataan kemerdekaan Indonesia. Untuk itulah sebuah panitia kecil dibentuk, yang anggota-anggotanya terdiri atas Sukarno, Hatta, Ahmad Subardjo, Muhammad Yamin, dan A.A. Maramis-tokoht Kristen (nasionalis sekuler), Abikusno Tjokrosujoso, A. Kahar Muzakkir, Agus Salim, dan A. Wahid Hasyim (nasionalis Islmai). Panitia kecil ini menyusun naskah pembukaan Pembukaan UUD, yang sekaligus merupakan sebuah kompromi antara golongan nasinalis dan Islam. Naskah tersebut disebut Yamin Piagam Jakarta (Jakarta Charter). Pada intinya Piagam ini mengesahkan Pancasila sebagai dasar negara dengan penambahan kalimat pada sila ketuhanan menjadi: Percaya kepada Tuhan dengan kewajiban menjalankan syariat

\footnotetext{
${ }^{20}$ A. Syafii Ma'arif, Islam dan Masalah Kenegaraan Percaturan di Konstituante, (Jakarta,
} LP3ES, 1986), h. 102

\footnotetext{
${ }^{21}$ Bahtiar Effendy dan Ali Munhanif, Indonesia Pasca Kemerdekaan, Volume, 5, h. 433
} 
Islam bagi pemeluk-peluknya. ${ }^{22}$ Tambahan inilah yang kemudian dikenal dengan tujuh kata dalam Piagam Jakarta.

Tampaknya, dalam sidang-sidang selanjutnya rumusan Piagam Jakarta ternyata jauh lebih sulit menawarkan dari pada merumuskannya. Rumusan Piagam Jakarta kembali dipersoalkan. Golongan Islam tetap ingin mempertahankan posisi mereka dengan menyatakan bahwa rumusan itu tidak cukup kuat menempatkan posisi Islam dalam mengatur negara. Karena alasan ini. Wahid Hasyim menegaskan bahwa hanya orang-orang Islam yang dapat dipilih sebagai presiden dan wakil presiden negara Indonesia ini. Lebih jauh ia juga menegaskan bahwa Islam harus diterima sebagai dasar negara. Sementara itu, seraya mendorong lebih kuat diterimanya gagasan negara Islam, Ki Bagus Hadikusumo menuntut agar sila ketuhanan berbunyi "Percaya kepada Tuhan dengan kewajiban menjalankan syariat Islam", tanpa prasyarat bahwa keharusan itu hanya berlaku bagi umat Islam. Sebaliknya, kelompok nasionalis menolak desakan kelompok Islam, karena khawatir terjadinya sikap diskriminatif yang akan timbul terhada agama lain. Latuharhary, seorang tokoh Kristen, Djayadiningrat, dan Wongsonegoro, menuntut agar dasar negara harus benarbenar dilepaskan dari ajaran agama tertentu.

Perdebatan baru mereda ketika Sukarno menyerukan agar kedua belah pihak bersedia berkorban, karena situasinya semakin mendesak untuk memikirkan Indonesia yang merdeka. Para anggota BPUPKI akhirnya bersepakat bahwa masa depan Indonesia merdeka akan didasarkan kepada rumusan Piagam Jakarta, yakni Percaya kepada Tuhan dengan kewajiban menjalankan syariat Islam bagi pemelukpemeluknya. Selain itu, mereka juga menerima Islam sebagai dasar negara, dan bahwa presiden Republik Indonesia harus seorang muslim. ${ }^{23}$ Kompromi politik ini, tampaknya menguntungkan kelompok Islam.

Kompromi politik dalam bentuk Piagam Jakarta hanya mampu bertahan selama kurang dari tiga bulan (1 Juni 1945-17 Agustus 1945). Anak kalimat pengiring Percaya kepada Tuhan yang terdiri dari tujuh kata (kewajiban menjalankan syariat Islam bagi pemeluk-pemeluknya) digugat oleh sebagian bangsa kita di belahan Timur Indonesia karena dianggap sebagai diskriminatif terhadap pemeluk agama lain. ${ }^{24}$ Maka demi persatuan bangsa,anak kalimat itu pada tangal 18 Agustus 1945 dibuang dari Pembukaan UUD 45.

Pada tanggal 18 Agustus 1945 sore, sehari setelah proklamasi kemerdekaan Indonesia, Piagam Jakarta kembali dipersoalkan. Dikisahkan, bahwa seorang pejabat Angkatan Laut Jepang datang menemui Hatta dan melaporkan bahwa penganut agama Kristen yang sebagian besar berdomisili di bagian Timur wilayah Hindia Belanda tidak akan bergabung dengan Republik Indonesia, kecuali beberapa unsur dari Piagam Jakarta, yakni kewajiban menjalankan syariat Islam bagi pemelukpemeluknya, Islam sebagai agama negara, dan persyaratan bahwa presiden harus

\footnotetext{
${ }^{22}$ Bahtiar Effendi dan Ali Munhanif, Indonesia Pasca Kemerdekaan, Volume 5, h. 433.

${ }^{23}$ Bahtiar Effendy dan Ali Munhanif, Indonesia Pasca Kemerdekaan, Volume 5, h. 433-434.

${ }^{24}$ A. Syafii Maarif, Islam dan Politik di Indonesia pada Masa Demokrasi Terpimpin (19591965), h. 28
} 
seorang muslim dihapuskan. ${ }^{25}$ Mereka berkilah bahwa penerapan Piagam Jakarta akan mengancam kegiatan sosial-keagamaan dan politik mereka. Bagi mereka kerangka konstitusi semacam itu akan mengakibatkan timbulnya kebijakan negara yang bersifat diskriminatif.

Sebenarnya, sidang Panaitia Persiapan Kemerdekaan Indonesia (PPKI) tanggal 18 Agustus 1945 adalah untuk menetapkan UUD serta memilih presiden dan wakil presiden. Dengan terjadinya keberatan sekelompok masyarakat di bagian Timur Indonesia itu, maka sebelum UUD ditetapkan, para pendiri negara ini terpaksa kembali melakukan tugas melelahkan dalam rangka memodifikasi dasar idiologi dan konstitusi negara. Dalam upaya ini, Muhammad Hatta menyarankan agar dibuat penyesuaian tertentu untuk menjamin kesatuan negara nasional Indonesia. Didorong oleh rasa persatuan serta atas desakan Hatta, Ki Bagus Hadikusumo, Wahid Hasyim,Kasman Singadimejo, dan Teuku Muhammad Hasan (semuanya diangap mewakili golongan Islam dalam PPKI) bersepakat menghapus unsur legalistikformalistk Islam dalam UUD 1945, terutama pencabutan butir mengenai Islam sebagai agama resmi negara, persyaratan bahwa presiden harus seorang muslim, dan kewajiban menjalankan Islam bagi pemeluk-pemeluknya; dan sebagai gantinya, dimasukkan ke dalam sila pertama unsur teologi monoteistik "Yang Maha Esa" sebagai atribut pengiring Ketuhanan, ${ }^{26}$ sehingga sila pertama Pancasila berbunyi Ketuhanan Yang Maha Esa.

Dengan fakta ini, kelompok Islam tetap meyakini bahwa kata Yang Maha Esa itu sebagai ganti tujuh kata dalam Piagam Jakarta yang dicoret, tetap melambangkan ajaran tauhid, pusat seluruh system akidah dalam Islam. Namun, dicoretnya beberapa kata unsur legalistik-formalistik Islam dalam UUD, meruapakan kekalahan politik kelompok Islam, karena pemeluk agama lain pun memiliki kebebasan menafsirkan sila pertama itu menurut agama mereka masing-masing.

Ada sejumlah dugaan mengenai mengapa wakil para golongan Islam bisa dengan mudah menerima penghapusan Piagam Jakarta-sebuah modus Vivendi konstitusional, yang untuk mencapainya mereka harus berjuang tanpa lelah di BPUPKI. Pertama, bersarnya kepercayaan kelompok Islam kepada Muhammad Hatta. Sebenarnya, Soekarno cukup kewalahan menghadapi golongan Islam, terutama Ki Bagus Hadikusumo yang tetap bertahan dalam rumusan Piagam Jakarta, maka melalui Hatta yang memanfaatkan Teuku Muhammad Hasan, wakil Sumatera dalam PPKI, dibujuklah Ki Bagus Hadikusumo agar melunakkan sikapnya. Akhirnya dalam tempo sekitar 15 menit saja, unsur-unsur legalistik-formalistik Islam dalam pembukaan UUD berhasil dihilangkan. Kedua, dimasukkannya kata "Yang Maha Esa" dapat dilihat sebagai langkah simbolik untuk menunjukkan kehadiran unsur monoteistik Islam dalam idiologi negara. Dalam hal ini, golongan Islam, terutama Wahid Hasyim amat yakin bahwa penambahan sifat monoteistik dalam Pancasila, merupakan cerminan-atau setidaknya sejalan dengan prinsip tauhid dalam Islam. Ketiga, situasi yang berkembang pasca proklamasi kemerdekaan, mengharuskan para

\footnotetext{
${ }^{25}$ Bahtiar Effendy dan Ali Munhanif, Indonesia PascaKemerdekaan, Volume 5, h. 434.

${ }^{26}$ Lihat Prawoto Mangkusasmito, Perumusan Historis Rumus Dasar Negara dan Sebuah Proyeksi, (Jakarta, Hudaya, 1970), h. 22.
} 
pendiri republik ini, bersatu menghadapi masalah lain. Yang paling penting diantaranya adalah upaya pemerintah Hindia Belanda untuk menduduki kembali Indonesia, harus diantisipasi. Keempat, didorong oleh rasa optimisme yang meyakinkan, karena konstituen dengan jumlah besar, para wakil Islam percaya bahwa lewat pemilihan umum yang akan diselenggarakan dalam waktu yang tidak lama lagi, mereka akan mempunyai kesempatan ulang untuk secara konstitusional menjadikan negara ini, negara Islam.

Karena alas an-alasan di atas, Ki Bagus Hadikusumo atas dukungan golongan Islam lainnya, seperti Kasman Singadimejo dan Wakid Hasyim, bersedia menerima usulan Muhammad Hatta. Kesempatan kedua memang jadi kenyataan pada sidang-sidang konstituante tahun 1956-1959, tetapi golongan Islam gagal lagi mewujudkan dasar negara Islam, karena presiden Soekarno keburu mengeluarkan Dekrit presiden tanggal 5 Juli 1959, untuk kembali kepada UUD 1945.

\section{Kesimpulan dan Rekomendasi}

1. Islam dan politik memang merupakan satu kesatuan yang tidak dapat dipisahkan. Islam dan politik terdapat korelasi fungsional, Islam memerlukan dukungan politik, sementara politik membutuhkan moral dan etika Islam. Hubungan antara Islam dan politik paling tidak dapat dilihat dari dua sisi. Pertama, dari sisi doktrin, terdapat beberapa ungkapan Alquran yang sering ditafsirkan sebagai konsep politik menurut Islam. Kedua, dari sisi realitas soaial kemasyarakatan. Pasca peristiwa hijrah tahun $622 \mathrm{M}$, Rasulullah SAW., telah membentuk pemerintahan Madinah melalui kontrak politik penduduk kota Madinah yang terdiri atas kelompok Yahudi, kelompok Islam, dan masyarakat Arab yang masih menganut tradisi jahiliah. Kontrak politik yang dituangan dalam sebuah shahifah, kemudian dikenal dengan nama Piagam Madinah.

2. Untuk menjembatani berbagai perbedaan antara golongan Islam dan golongan nasionalis sekuler dalam BPUPKI yang merancang Pembukaan UUD dan pernyataan kemerdekaan Indonesia. Sebuah panitia kecil dibentuk, sekaligus merupakan kompromi antara golongan nasinalis dan Islam. Panitia kecil ini, berhasil merumuskan Naskah Piagam Jakarta (Jakarta Charter). Pada intinya Piagam ini mengesahkan Pancasila sebagai dasar negara dengan penambahan kalimat pada sila ketuhanan menjadi: Percaya kepada Tuhan dengan kewajiban menjalankan syariat Islam bagi pemeluk-peluknya. Kompromi berikutnya terjadi pada 18 Agustus 1945, mengubah anak kalimat Ketuhanan dengan kewajiban menjalankan syariat Islam bagi pemeluk-pemeluknya, menjadi "Ketuhanan Yang Maha Esa".

\section{Rekomendasi}

Dengan terjadinya kompromi antara kelompok nasionalis sekuler dan kelompok Islam mengenai masalah Dasar Negara Indonesia Merdeka, yaitu Pancasila. Maka diharapkan kedua kelompok tersebut bersama-sama memperjuangkan pelaksanaan Pancasila secara murni dan konsekuen, tidak saling menafikan satu dengan lainnya. Kelompok Islam, melaksanakan Pancasila sesuai dengan agamanya, dan kelompok nasionalis sekuler tidak memandang Islam mengancam keutuhan 
bangsa dan menghalang-halangi umat Islam menjalankan syariat agamanya sepanjang tidak bertentangan dengan pancasila.

\section{Daftar Pustaka}

Azra, Azyumardi. Jaringan Ulama Timur Tengah dan Kepulauan Nusantara Abad XVII dan XVIII Melacak Akar-Akar pembaruan Pemikiran Islam di Indonesia, (Bandung, Mizan, 1994)

Benda, Harry J. The Cresent and the Rising Sun, diterjemahkan Dhaniel Dhakidae: Bulan Sabit dan Matahari Terbit Islam Indonesia pada Masa Pendudukan Jepang, (Jakarta, Pustaka Jaya, 1985)

Effendi, Bahtiar dan Ali Munhanif. Indonesia Pascakemerdekaan, dalam Taufik Abdullah dkk (ed), Ensiklopedi Tematis Dunia Islam, Volume 5.

Hamka, Masuk dan Berkembangnya Agama Islam di Daerah Pesisir Sumatera Utara, dalam Risalah Seminar Masuknya Islam ke Indonesia, (Medan, Panitia Sejarah Masuknya Agama Islam ke Indonesia, 1963)

Hurgronye, C. Snouck. Kumpulan Karangan, Jilid x, (Jakarta, Inis, 1993).

Iqbal, Muhammad dan Amin Husein Nasution. Pemikiran Politik Islam: dari Masa Klasik hingga Indonesia Kontemporer (edisi revisi, cet. 2, Jakarta, Kencana, 2013)

Iskandar, Muhammad dan Ahmad Syahid. Islam dan Kolonialisme, dalam Taufik Abdullah dkk (ed), Ensiklopedi Tematis Dunia Islam, Volume 5, h. 322.

Ma'arif, A. Syafii. Islam dan Masalah Kenegaraan Percaturan di Konstituante, (Jakarta, LP3ES, 1986).

Maarif, Syafii. Islam dan Plotik di Indonesia Pada Masa Demokrasi terpimpin (19591965), (Yogyakarta, IAIN Sunan Kalijaga Press, 1988)

Mangkusasmito, Prawoto Perumusan Historis Rumus Dasar Negara dan Sebuah Proyeksi, (Jakarta, Hudaya, 1970), h. 22.

Poespenogoro, Marwati Djoened dan Nugroho Notosusanto. Sejarah Nasional Indonesia III, edisi ke-4 (Jakarta, Balai Pustaka, 1984)

Putuhena, M. Saleh Ahmad. Islam dan Politik Pergumulan Tanpa Akhir Rekonstruksi Pantulan Pengalaman Indonesia. (Makassar, IAIN Alauddin, 2004)

Putuhena, M. Saleh Ahmad. Islam dan Politik: Pergumulan Tanpa Akhir, Rekonstruksi Pantulan Pengalaman Indonesia (Pidato Penerimaan Jabatan Guru Besar Sejarah dan Kebudayaan Islam pada Fakultas Adab IAIN Alauddin Makassar, Makassar, 11 Nopember 2004)

Suminto, Akib. Politik Islam Pemerintah Hindia Belanda, (Jakarta, LP3ES, 1996).

Tjandrasasmita, Uka. Kedatangan dan Penyebaran Islam, dalam Taufik Abdullah dkk (ed), ensiklopedia Tematis Dunia Islam, Volume 5, (Jakarta, PT Ikhtiar Baru Van Hoeve, 2003) 